AGH DRILLING, OIL, GAS • Vol. $30 \cdot$ No. $1 \cdot 2013$

http://dx.doi.org/10.7494/drill.2013.30.1.181

Andrii Oliinyk ${ }^{* *}$, Mariusz Laciak*

\title{
SAFETY TECHNICAL PROBLEMS \\ ASSOCIATED WITH THE STORAGE OF LIQUEFIED NATURAL GAS (LNG)
}

\section{INTRODUCTION}

The world economy fast growth over the last several dozen years has caused the need for the new energy sources, among which is natural gas. Enormous distances between the gas sources and end users and the lack of pipelines contribute to LNG technology development.

Liquefied natural gas or LNG is natural gas (predominantly methane, $\mathrm{CH} 4$ ) that has been converted to liquid form for ease of storage or transport.

Liquefied natural gas takes up about 1/600th the volume of natural gas in the gaseous state. It is odorless, colorless, non-toxic and non-corrosive.

The liquefaction process involves removal of certain components, such as dust, acid gases, helium, water, and heavy hydrocarbons, which could cause difficulty downstream. The natural gas is then condensed into a liquid at close to atmospheric pressure by cooling it to approximately $-162^{\circ} \mathrm{C}$.

LNG achieves a high reduction in volume. This makes LNG cost efficient to transport over long distances where pipelines do not exist. Specially designed cryogenic sea vessels (LNG carriers) or cryogenic road tankers are used for its transport.

\section{THE POTENTIAL HAZARDS WITH LNG STORAGE}

LNG properties, such as very low temperature $\left(-162^{\circ} \mathrm{C}\right)$, increasing volume after evaporation (about 600 times) cause that, the LNG is quite dangerous medium. Amount of potential threats connected with LNG, increase with its quantity. It causes that, the LNG

* AGH University of Science and Technology

** Student of AGH UST 
magazines are the biggest potential threat for humans and environment due to accumulation of large amounts of LNG on a small area.

\section{Explosion}

Explosion is a process, of fast uncontrolled transition from one state to another, connected with emission substantial amounts of energy as a mechanical work.

In LNG case it could be connected with rapid change of its chemical properties, ignition or uncontrolled release of its portion. Cause of such a release of liquid could be storage tank leak. LNG is stored in tanks under atmospheric pressure, so even in case of small leakage there isn't large hazard of immediate formation explosive, gas - air mixture.

Ignition and explosion of gas - air mixture, formed due to LNG leakage, could occur when concentration of natural gas in cloud volume would be in $5-15 \%$ range. This range is called explosion limits, lower and upper. Explosion limits are influenced by many factors such as: pressure and temperature, energy of ignition source, share of inert or active ingredients etc.

Temperature of self - ignition is also important. It is the lowest temperature, which cause self-spreading of flames. Temperature higher than self - ignition temperature could cause ignition even after short exposition. Very high temperatures and concentration of gas in explosion limits could cause immediate ignition. Lower explosion limit is influenced by: gas dopants, some metals and conditions it occurs. In comparison with other liquid and gas fuels, LNG fumes (methane) have much higher self - ignition temperature.

\section{Clouds of LNG fumes}

In case of leak LNG out of the tank over the leakage surface forms the cloud of the fumes. Released LNG cloud spreads just above terrain surface, when it encounters efficient ignition source on its route, it could cause explosion of cloud in unlimited space.

Concentration of natural gas in released LNG cloud, varies from $100 \%$ in the center of the cloud, to very low concentrations on its edges.

Physical size of, released LNG cloud, range depends on mass of the LNG, period of diffusion and atmospheric conditions. On the cloud edges, there could appear space, where concentration of natural gas would be between lower and upper explosion limit, which provides explosive atmosphere. After evaporation of whole LNG, gas concentration in the cloud would gradually reduce and after some time it will be under the lower explosion limit so there won't be explosion hazard.

In released LNG cloud, on the open space (no limits such as walls for example than walls decreases maximal explosion pressure and accelerate its drop), flammable gas burns slowly thereby generating low overpressure with values under $5 \mathrm{kPa}$. Higher overpressure values generated during LNG cloud explosion could occur in highly urbanized regions.

Fumes cloud ignites only if it encounters source of ignition in range of its explosion limits. Safety devices and operating procedures are intended to minimize probability of releasing another fume clouds, which could flow outside object area. 


\section{Low temperature}

Low temperature of cryogenic liquids in comparison with environment temperature requires usage of special resources. In order of releasing LNG, in direct human contact with cryogenic liquid there could occur contact frostbite. Due to this fact each employee of the object, have to be equipped with appropriate protective clothing, gloves, masks and other requested safety measures preventing from frostbites. This threat is limited to object area and it doesn't affect nearby area.

\section{'Rollover' effect}

Beside pressure and temperature there is other factors stimulating instability of stored medium:

- Storage LNG for long periods, which may take place when stored LNG is used to cover seasonal shortages of gas,

- Various quality of stored LNG,

- Cyclic pumping in and out processes,

- High nitrogen content in stored LNG.

One of this factors or its combination could cause the phenomenon of delamination liquidized natural gas inside the tank - rollover. By this phenomenon we should understand very rapid evaporation of methane from LNG storage tank, caused by delamination of liquid and following rolling inside that tank. Risk of delamination cryogenic liquid occurs, when there are two separated layers with various densities in one tank ( various densities are caused of differences in LNG composition).

Liquid in upper, lighter layer is heated as a result of heat supply from the outer environment, then it migrates up to the surface and its evaporates. Firstly light hydrocarbons evaporate. After prolonging heating changes of mixture composition causes vital density change. Upper layer becomes heavier and heavier. Liquid in lower layer, also heated moves nearby separation line. Because of hydrostatic pressure caused by upper layer it couldn't evaporate. It makes lower layer lighter and warmer. When both of the layers take similar densities they will mix rapidly. After lower - overheated layer gets to the surface, it causes very sudden and intense evaporation of large amount of methane. This phenomenon is called - rollover.

Main hazards connected with rollover is evaporation of large amounts of methane which may cause appearance of overpressure inside the magazine tank.

There are several ways of reducing probability of occurring the rollover. One of them is proper filling of the tanks. In case of transferring products which density is various from liquid inside the magazine tank it is recommended to put lighter LNG lower and heavier upper. Another important factor is reducing heat inflows during transfer LNG from methane tanker ships inside the storing tanks. Sometimes it is even recommended to proceed condensation of a liquid once again before inserting liquid into the tank. Another possible solution is continuous operation of recirculation pumps. In order to properly, early detection of liquid delamination and possible sudden evaporation, most of the tanks is equipped with 
precise sensors recording density and temperature of a liquid as a function of depth. Thanks to it we could quite accurate describe what's happening inside the tank and could react properly on any distress.

\section{TECHNICAL SECURITY}

The safety of the LNG storage facility is of particular importance due to the presence of the mentioned above potential hazards.

The safety underlies of multilevel security, creating four critical areas of safety integrated with standards of the branch and rules.

A primary containment. The first and the most important requirement of protection is to provide safe accumulating of LNG. It is achieved by using concrete materials for building gasholders and machines, also by performing correct and adequate technical project on each technological stage.

A secondary containment. This level of security ensures that in case of leakiness or spillage it will appear its isolation and security. On the land it can be as a form of dams or earthworks placed around liquid tanks to capture the product on account of spillage. The height of embankments, which goes with the installation building after 1980, exceeds in general $8 \mathrm{~m}$.

In some installation, the outer embankment surrounds the adequate internal embankment containing the LNG. The external system has a density far in excess of the density of a proper embankment. With the solution, the necessity of building dams and earthworks is eliminating.

The security systems. The target of the third level of security is minimalization of the LNG spill frequency as well as mitigation the reasons of leak. On this stage of security, LNG operators use system of detecting, among other things, gases, the liquid vapors, fire, etc. able to quickly identify each danger and next remotely and automatically turn off or stop concrete technological process in order to minimize amount of leakiness and spillage of LNG.

The separation distances. The main rule of installation planning is removal the people from risky areas. The rules should require a localization of LNG installation in the safe distance from the neighborhood of industries, settlements, public places and the other areas of this type. All offices and technical faculties should be placed at enough distance from a storage tank. To direct service of installation, it is required to use automatic systems which allow for centrally control of the process and eliminate the necessity of constant fulfilling the service in hazardous places. The safe distances or excluded areas, chosen based on a data which determines levels of LNG vapor concentration.

The standards of branch, accordance with rules. The norms and orders are aimed at allowing officials in more effective opinion of safety and influence on surroundings of 
installation as well as industry's action. A compatibility with rules should require clarity and responsibility in public domain. The security system will be never complete without adequate operation procedures and assurance that they are abided, and assurance of disposing sufficiently trained staff.

\section{THE CONSTRUCTION PROTECTION OF LNG STORAGE TANKS}

The LNG tank should fulfill below mentioned requirements:

- allow for safe storage of LNG depending on minimal pressure to calculate pressure,

- keep without negative results of cooling the tank and cycle filling and emptying the tank by liquid gas,

- provide proper isolation and tightness.

For the sake of very low temperature of at least medium storage, selection of the materials, which are then used to build the tank, has a large importance.

An internal tank of LNG, build of a special material that characterized of keeping suitable properties in very low temperatures. The outer tank is made of the coal steel or compressed concrete. The most important role plays an interior tank because being in connection with the LNG it has to move its weight in the temperature to the minus 162 Celsius keeping tightness and reliability in exploitation.

The austenitic steels, steel that consists of 9 percent of nickel, aluminum and invar, should be attached to the materials which are used for an internal tank. The steels with content of 9 percent of $\mathrm{Ni}$ are the most used materials for internal tanks. The membrane tanks are usually built of austenitic steel. A proper selection of materials and usage of suitable methods of their connection decide about safe and long lasting work of tanks. From the steel of internal tanks is required a resistance to fragility cracking in low temperatures and owing abilities of preventing cracks' spreading. The roofs of internal tanks are light, mostly construct of aluminum. The external tanks are made of the coal steel or compressed concrete in general.

A very important element of LNG tank construction is its thermal isolation. The used isolation materials ought to provide the smallest thermal conductivity, and according to it, low natural vaporization of condenses gas. The bottom of the tank is isolated with foamglass with thermal conductivity $0.042 \mathrm{~W} / \mathrm{m} \cdot \mathrm{K}$. The space between cylindrical part of inner and outer tanks is filled with perlite with thermal conductivity of $0.025 \mathrm{~W} / \mathrm{m} \cdot \mathrm{K}$ which is filled through stub pipe in the roof of tank. Spraying of the inner tank wall with polyurethane with thermal conductivity of $0.032 \mathrm{~W} / \mathrm{m} \cdot \mathrm{K}$ is often used. On the outer surface of the inner tank fiberglass mat is installed with thermal conductivity $0.046 \mathrm{~W} / \mathrm{m} \cdot \mathrm{K}$ and a thickness of $250 \mathrm{~mm}$. For insulation of the flat roof of the inner tank fiber glass with a thickness of $2000 \mathrm{~mm}$ is used.

Even the best-designed construction cannot meet the requirements if the equipment, materials and manufacturing techniques don't meet the quality requirements. That's why 
before putting storage tank into operation a series of qualitative research must be carried out. Checking the welded joints of tanks is an important part of the quality system and includes various types of research and trials. Finished inner tank must be hydrostatically tested. Pressure and partial vacuum tests are conducted after installing pipelines and control and measuring systems.

Another factor that has a major impact on the safety of LNG storage in addition to the above-mentioned aspects is the design of the tank. The design of the tank resembles a thermos built on a slab foundation which must be properly insulated and heated.

Due to the construction of LNG storage tanks are divided into three main types:

- Single containment tank SCT consists of a suitable cryogenic metal inner container (economics currently favor 9\% nickel steel) designed to hold the LNG, with a carbon steel outer tank designed to contain the natural gas vapors. A secondary means of LNG containment is generally provided, such as an engineered earthen dike.

- Double containment tank DCT is essentially a single containment tank surrounded by a close-in, reinforced open top concrete outer container designed to contain any spill or leak from the inner tank, but not to hold any vapor released during a spill.

- Full containment tank FCT, this type of tank is similar to the previous two, with the difference that the construction of the outer container housing and the roof is a cupola made of prestressed concrete.

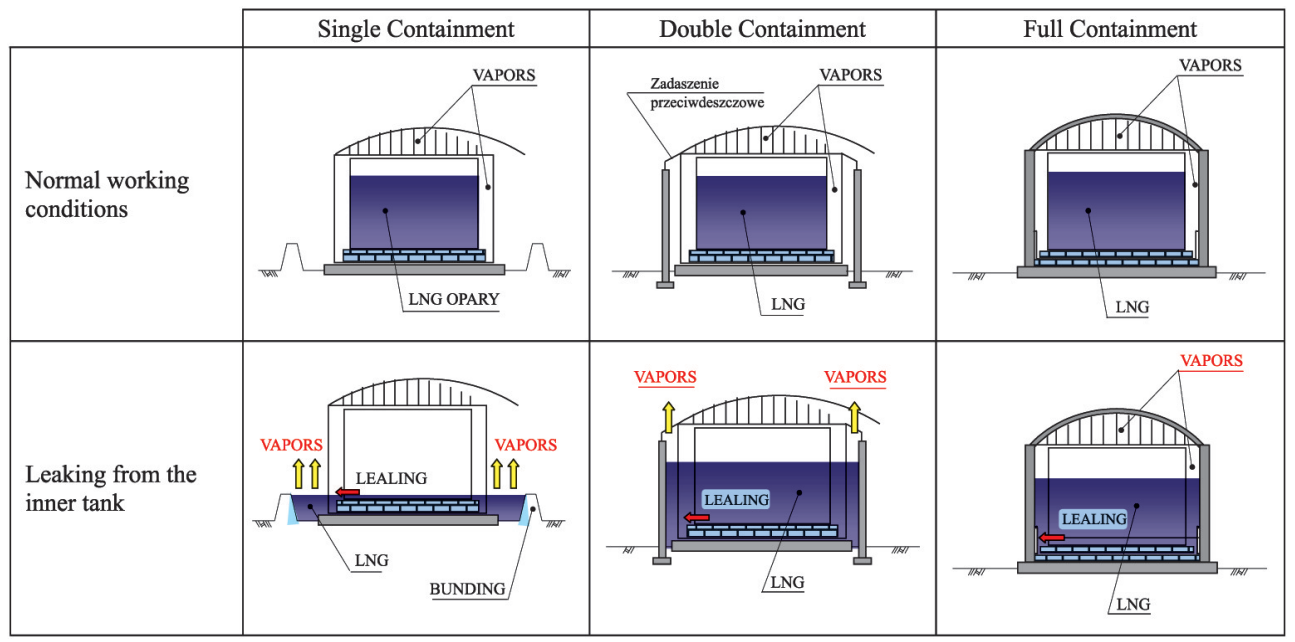

Fig. 1. Types the construction of tanks [5]

The unique feature of single containment tank SCT is the fact that only the inner tank shall fulfill the condition of the low temperature toughness of the product during storage of LNG. Steel outer tank should hold and protect the cryogenic insulation and accomodate vapor gas, but not spilled LNG. 
Protection against spills from single containment tanks is based on building a special bunding. It is designed to prevent the spread of spilled fluid outside the defined area. In order to retain all the storage volume, the volume limited by the bund wall must be greater than the geometric volume of the tank. In the case of leakage of LNG vapor will escape into the atmosphere, which is the biggest drawback of this type of design solution.

The bottom and walls of the inner tank are constructed of steel with a $9 \%$ nickel content. This helps to prevent shrinkage. The bottom and walls of the outer tank are made of ordinary steel. The space between the walls is filled with perlite for better isolation. For the insulation of space between the bottom of the inner tank and the slab foundation, which lies under the bottom of the external tank, glass wool is usually used. To separate the bottom of the tank from glass wool insulation a special concrete is used. To reduce the load that acts on the slab foundation the inner tank wall is mounted on a specially prepared foundation ring.

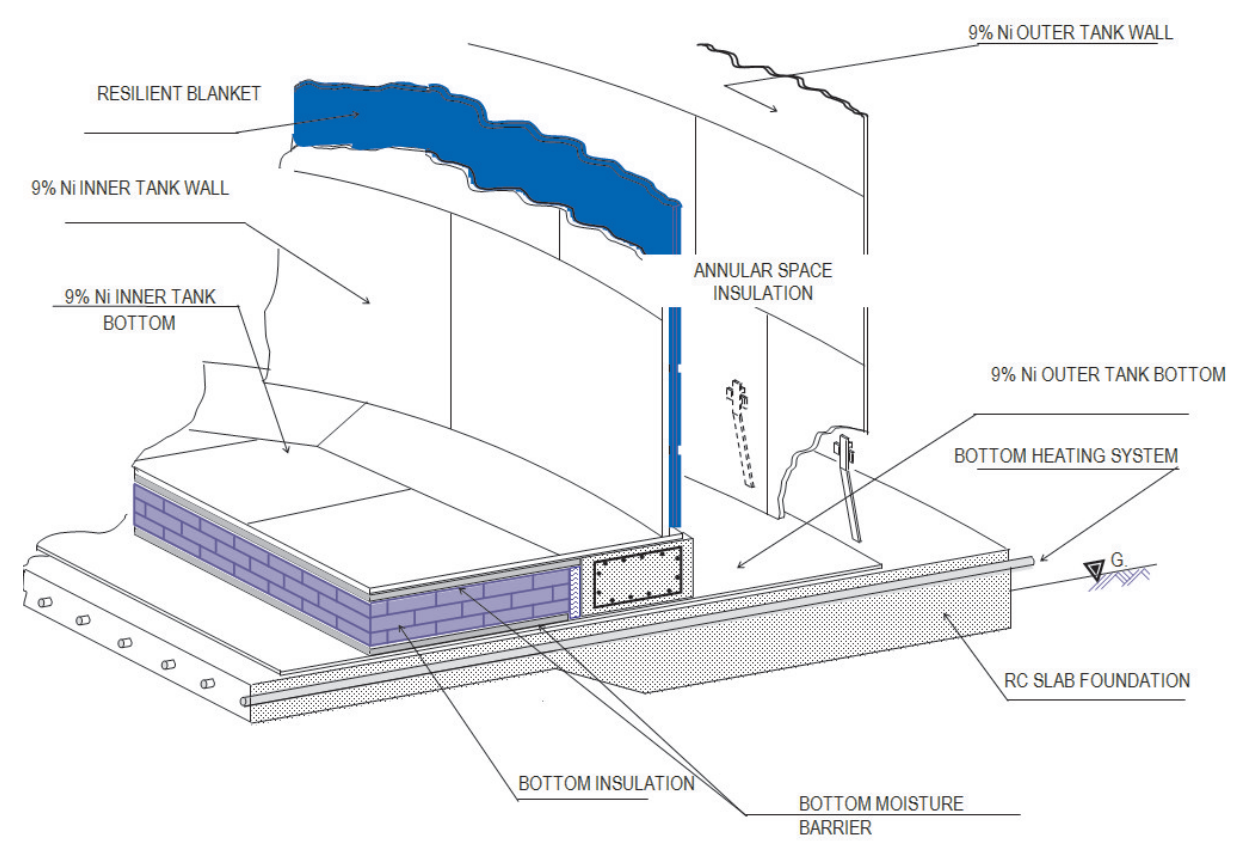

Fig. 2. Single Containment tank [5]

The full containment tanks turn out to be the most effective solution. The full containment tank is designed so that both the inner and the outer tank are able to accommodate LNG spills. External tank is properly designed to accommodate the spilled LNG as well as controlled removal of the resultant vapor.

Construction of full containment tank is similar to the the construction of single containment tank, except that both the inner and the outer tank structure is made of steel with a $9 \%$ nickel content. Because the inner and the outer tank must ensure inaccessibility in the 
storage of LNG, the outer tank wall is supported by lateral surface of prestressed concrete. To prevent penetration of vapor into the concrete the barrier of carbon steel is placed between them. In order to reduce the heat transfer the walls and the bottom of the outer tank can also be isolated with a glass wool.

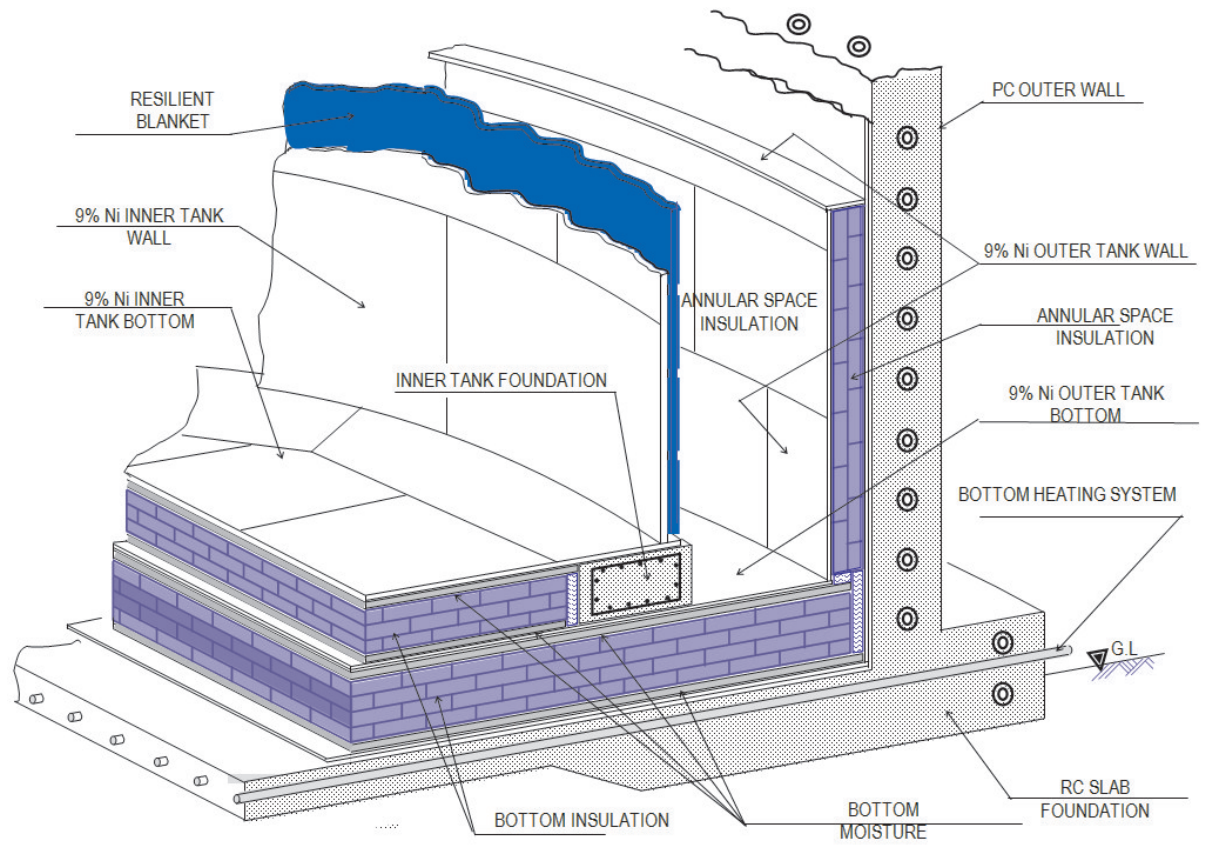

Fig. 3. Full Containment tank [5]

Double containment tanks are a transitional form between the single and full containment. Double containment tanks as opposed to only have full containment breaker protection (no protection against vapors escaping into the atmosphere in case of overflow).

The inner tank and the outer tank should be independently accommodate LNG. In order to minimize the leakage area, the outer tank is located at a distance of no more than 6 meters. The inner tank contains the product LNG in exploatations conditions. The purpose of the outer tank is catching LNG leakage from the inner tank but not the vapors.

Each LNG installation is equipped with several safety devices which can be divided as follows:

- Accident prevention devices and eliminating their consequences (egpressure relief valve (PRV), automatic circuit devices, systems of gathering pipelines and leaks from the system, etc.).

- Devices that detect and indicate any irregularities in the operation of the system, (such as gas and fire detectors, sirens and temperature alarm systems, critical monitoring of the installation).

- Equipment for fighting fire (including water and powdercannon). 


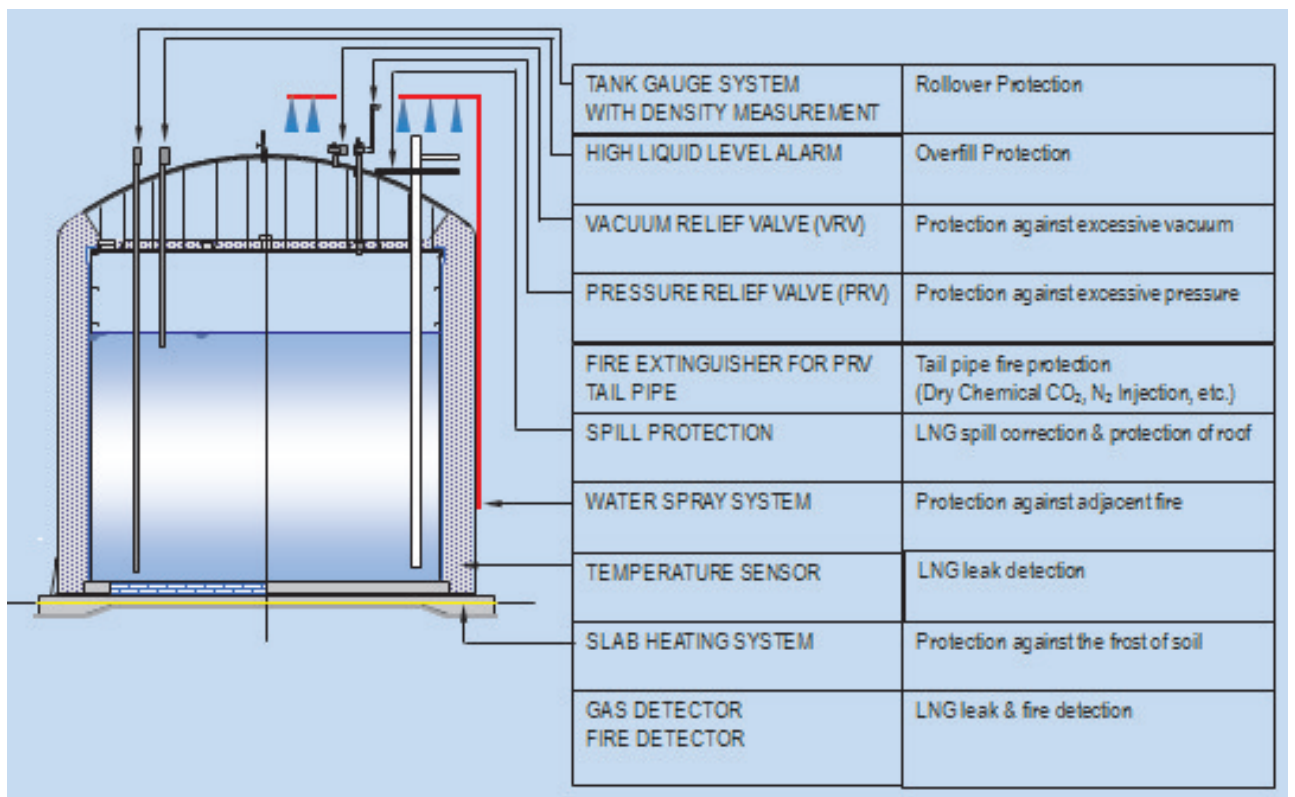

Fig. 4. Basic security LNG tank [5]

The pressure in the tank usually ranges within the limits of 120-400 mbar. Maintain a safe working pressure of the tank is ensured by a system of safety valves installed on the tank. Working pressure is controlled by a dual system of pressure relief valves.

The tanks must be equipped with a system of checks and safeguards to ensure their safe exploatation. Addition to these pressure control devices, the tanks are equipped with temperature control devices at different points in the tank, measuring the density and level of LNG.

The density at various points in the tank is measured in order to prevent delamination of the liquid in the tank. For the same purpose also the temperature is measured at different depths. On the tanks are mounted high liquid level alarm. This is done to prevent stroke liquid when filling the tank. At the outlet of the pressure relief valve is mounted fire extinguisher for PRV tail pipe. Quenching is carried out by injecting carbon dioxide or nitrogen. Sprinklers of the tank is used to cool the tank in the event of fire on the outside.

\section{CONCLUSIONS}

Because of the very low storage temperatures $\left(-162^{\circ} \mathrm{C}\right)$, liquefied natural gas to be treated as a hazardous substance, and the infrastructure for the storage poses the greatest threat in comparison with the rest of the chain of production and distribution of LNG. The potentially most dangerous risks associated with the storage of LNG are: explosions, vapors of LNG, frostbite, stratification of liquefied natural gas in the tank and the rapid evaporation 
of LNG. The minimization of the above-mentioned risks can be achieved by compliance with security requirements during the design, construction and operation of the tanks. Choosing a good location of the tank, it's design and the right materials and methods of combining them gives rise to accident-free operation of the tanks. Adherence to applicable standards and regulations in the technical operations of the LNG storage and keeping of the service reduces the probability of failure to a minimum.

\section{REFERENCES}

[1] Łaciak M.: Bezpieczeństwo eksploatacji urzadzeń, instalacji i sieci gazowych. Wyd. TARBONUS, 2010.

[2] Łaciak M. i in.: Instalacje i sieci gazowe. Wydawnictwo Verlag Däshofer, Warszawa 2013.

[3] Puchaczewski A.: Zasady doboru stali na zbiorniki pracujqce $w$ niskich temperaturach. Konferencja na temat zbiorników naziemnych, Zakopane 1995.

[4] PN-EN 1473:2007: Instalacje i urzadzenia do skroplonego gazu ziemnego, projektowanie instalacji ladowych.

[5] PN-EN-1473 I_BS 77771993 - Flat-bottomed, vertical, cylindrical storage tanks for low temperature service. Część 1, 2, 3 i 4.

[6] EN 1160:1996: Installations and equipment for liquefied natural gas. General characteristics of $L N G$. 